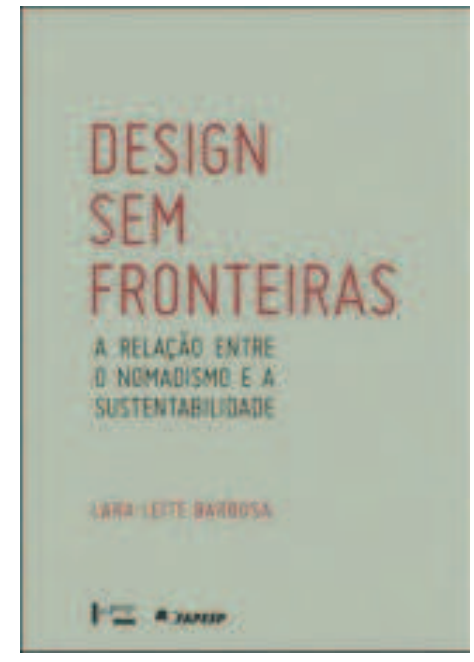

DESIGN SEM FRONTEIRAS:

A RELAÇÃO ENTRE O

NOMADISMO E A

SUSTENTABILIDADE

Barbosa, Lara Leite, Edusp, 308 P.

ISBN I0: $85-3$ I 4-I3I6-8

ISBN I3: 978-85-3I4-I3I6-2

Marcos Beccari

\title{
Fissuras Que SE ABREM A PARTIR DE UM PONTO SEM PERÍMETRO
}

1 MERLEAU-PONTY, M. O visível e o invisível. São Paulo: Perspectiva, 1992, p. 156.
Interrogamos nossa experiência, precisamente para saber como nos abre ela para aquilo que não somos. Isso não exclui nem mesmo que nela encontraremos um movimento em direção àquilo que não poderia, em hipótese alguma, estar-nos presente no original, e cuja irremediável ausência incluir-se-ia no número das nossas experiências originárias. Simplesmente, quando mais não fosse para ver estas margens da presença, para discernir estas referências, para pô-las à prova ou interrogá-las, é preciso fixar de início o olhar sobre aquilo que nos é aparentemente 'dado'. - Merleau-Ponty. ${ }^{1}$

É comum a sensação de morar numa cidade e, mesmo depois de anos, sentirse turista nela. Nasci em São Paulo e no fim da adolescência me mudei para Curitiba, onde morei durante quase dez anos. Retornei a São Paulo para prosseguir com meus estudos, mas voltarei à Curitiba logo mais, para lecionar. Neste vai-e-volta, é necessário desfazer-me de muita coisa, como móveis e eletrodomésticos. Pessoas, coisas e lugares mudam e são substituídos. Perdem-se alguns contatos, criam-se novos vínculos e mantêm-se algumas relações. No entanto, é preciso carregar algo não descartável, ainda que simbólico, ainda que impreciso.

Por mais que eu tenha esquecido muita coisa, e por mais que muita coisa tenha mudado, é como se eu nunca tivesse saído daqui. Minha memória não cessa de equivocar-se, tento imaginar o que aconteceu naquela praça ou padaria, como se as ruas fossem incapazes de evocar exatamente aquilo que eu vejo nelas. Mas o que afinal eu vejo? Não aquilo que eu vira antes, mas a maneira como eu vi: um momento diferente de todos os outros.

Difícil é compreender que a relativa "segurança" enunciada pela memória não se opõe à incerteza constitutiva da percepção das mudanças. Viver nos centros urbanos, pelos mais diversos motivos, implica uma necessidade ora 
2 BERGER apudBARBOSA,

L. L. Design sem fronteiras: a relação entre o nomadismo e a sustentabilidade. São Paulo: Editora da USP Fapesp, 2012, p. 34.

${ }^{3}$ Doutora em Arquitetura e Design pela FAUUSP professora no Departamento de Projeto da FAUUSPe

coordenadora do grupo NOAH (Núcleo Habitat sem Fronteiras), onde desenvolve e orienta pesquisas sobre Design para situações emergenciais na FAU-USP.

${ }^{4}$ BARBOSA, op. cit., p. 13

${ }^{5}$ Idem, p. 16.

6 KALTER, J. The Arts and Crafts of Turkestan. Londres: Thames \& Hudson, 1984

7 AGAMBEN, G. O que éo contemporâneo? e outros ensaios. Chapecó: Argos, 2009, p. 55.

8 Nomadismo, invisibilidade, desaparecimento, fuga ou desterritorialização são noções discutidas à exaustão por pensadores como Foucault e Deleuze e coadunam-se com um sutil "devir-

revolucionário", uma fuga que não é exatamente viajar, nem mesmo sair do lugar, mas "traçar linhas de fuga pelas margens": diz-se que nada mudou e, no entanto, que tudo mudou, só que de maneira irrastreável ao olhar histórico.

9 “[...] que transpõem os limites invisíveis que separam estados, países e continentes como os navegadores que percorrem mares onde as fronteiras estão dissolvidas" (BARBOSA op. cit., p. 14). esporádica ora frequente de mudar de lugar, endereço e casa. E o desejo de retornar, também recorrente, não consiste em evocar situações do passado, mas sim em reconstruí-las sem substituí-las, mediante novas situações que assim se tornam tão mais familiares quanto menos remetem a situações já conhecidas.

Creio que este aparente paradoxo possa se dissolver no enunciado de que "o lar não é um endereço, lar é o que eles [os nômades] carregam consigo". ${ }^{2}$ Eis a premissa para um design sem fronteiras, título da tese de doutorado de Lara Leite Barbosa $^{3}$, orientada por Maria Cecília Loschiavo dos Santos, publicada pela Edusp e Fapesp em 2012 e premiada com o $1^{\circ}$ lugar no Prêmio do Museu da Casa Brasileira 2009 e com o $3^{\circ}$ lugar do Prêmio Jabuti 2013 na categoria Arquitetura e Urbanismo.

A proposta apresentada pela autora foi basicamente a de relacionar os conceitos de nomadismo e sustentabilidade. Com relação ao primeiro, foca-se na experiência nômade de tempo e espaço, não restrita a um local específico ou às distinções entre passado, presente e futuro - "As medidas nômades são subjetivas e arraigadas ao local onde as experiências foram vivenciadas". ${ }^{4}$ No que diz respeito à sustentabilidade, o movimento cíclico é enaltecido em sistemas diversos (social, econômico, intersubjetivo, político etc.) que se retroalimentam.

O desafio deste livro consiste em auxiliar o leitor consciente do excesso de deslocamentos aos quais estamos sujeitos na vida contemporânea e do crescente número de jornadas, seja para o trabalho, seja para o lazer, capacitando-o a realizar escolhas mais apropriadas. Acumular muitas coisas torna o movimento mais pesado e difícil, principalmente para transportá-las. Uma alternativa seria ter acesso a elas sem a necessidade de possuí-las. ${ }^{5}$

Falar de nomadismo é ainda um desafio. Primeiro porque, conforme Kalter, ${ }^{6}$ o termo nômade não foi introduzido na linguagem acadêmica até o século 18. Ainda não conseguimos "mapear" muita coisa dos nômades - que não são somente povos migrantes ou viajantes, mas antes sem-território - simplesmente porque eles não se preocupam, ao menos sob um viés "moderno", com o passado ou o futuro. Em vários aspectos, eles são invisíveis: estão o tempo todo partindo, evadindo, passando - não de maneira passiva nem ativa, mas adaptativa, reconstruindo continuamente a experiência de "estar".

Em segundo lugar, as implicações do êxodo que caracteriza o comportamento nômade não se resumem a um instante permanente, mas antes se referem a um estar simultâneo em tempos ou circunstâncias diferentes. O filósofo Giorgio Agamben ${ }^{7}$ é contundente ao afirmar que contemporâneo é o que não coincide com seu tempo, que está um pouco "fora de lugar", o que presume certo distanciamento daquilo que no presente não podemos viver e, "restando não vivido, é incessantemente relançado para a origem, sem jamais poder alcançá-la".

Neste sentido, embora seja difícil de "falar sobre", parece-me que certa conduta nômade ${ }^{8}$ tem influenciado as pessoas de forma parcialmente contingencial - pelo menos, mais do que antigos ideais de Progresso e Revolução. Sobretudo no que diz respeito a refugiados, viajantes, imigrantes e exilados, ${ }^{9}$ a ideia de "bem-estar" passa a ser pautada na contingência do contexto e da situação, por meio de indivíduos e comunidades que se auto-organizam em plataformas provisórias (de trocas de favores, por exemplo). A ponte com a sustentabilidade então se instaura com a prevalência do contexto/situação sobre as ações a serem tomadas. 


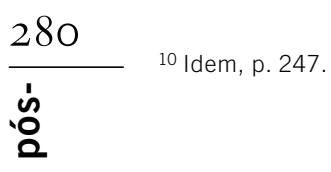

No período helenístico, a construção em pedra e cal significava, aos romanos, o "eterno", ao passo que a madeira representava o efêmero, o precário, o provisório. Para os então chamados "povos bárbaros" de origem saxônica ou eslava, por outro lado, a madeira constituía a matéria-prima fundamental. Tal valorização da madeira elucida o aspecto sistêmico do que atualmente denominamos "sustentabilidade": não retirar do meio aquilo que nele não pode ser reposto e nem produzir mais do que o meio é capaz de absorver. A ideia é manter um meio que ser conserva num ritmo que permita sua continuidade e expansão.

O que Lara Leite Barbosa oportunamente percebeu e demonstrou é que tal lógica não se opõe ao comportamento nômade de deixar lugares para trás. Pois na verdade não há nada deixado para trás, há apenas circunstâncias que determinam o que podemos ou não "carregar" conosco. Por conseguinte, o meio não se reduz a um espaço fixo, mas se reconfigura na medida em que passamos por ele.

Trata-se de um percurso cíclico incorporado pela própria estrutura do livro: partir; reconhecer o local e conhecer os outros; buscar os recursos; definir a duração e refletir sobre as estratégias que adotou para a próxima jornada. Assim os capítulos estão organizados, entre a introdução e a conclusão. No primeiro capítulo, o processo de desmontagem é analisado como recurso de transporte. Em seguida, o segundo capítulo aborda processos de integração e adaptação em relação às ambientes diversos. No terceiro capítulo, investiga-se a aquisição de recursos básicos em situações de mobilidade. O quarto capítulo explora as implicações de uma estética nômade na vida cotidiana e, por fim, questiona-se no quinto capítulo a noção de "conforto" em meio a estratégias nômades.

Entre tantas questões levantadas, acredito que o livro contribui principalmente em duas direções: ao pensamento sobre design e ao pensamento sobre a vida contemporânea. Em relação ao design, a própria noção de "projeto" como ação com princípio e fins bem definidos é colocada em xeque por uma "linha do meio", uma linha de tensão que só pode ser apreendida enquanto ela é traçada e recomeçada. No último capítulo, essa linha se torna clara: apesar de altos investimentos em habitações emergenciais (para situações de desastres como terremotos ou enchentes), há alguns resultados não previstos em tais projetos, como a não aceitação de casas pré-fabricadas por parte de populações locais. Constatou-se que a importação de recursos é mais cara e mais lenta do que a construção local, de modo que o uso de tendas de acampamento tem sido mais eficaz e bem aceito como habitação provisória.

Classificada como desnecessária e indesejável, a construção de habitações para situações de desastre é substituída pela provisão de abrigos de emergência em paralelo com a reconstrução das casas. A intenção é restaurar a vida que a pessoa tinha antes do desastre, assegurando que as decisões sobre o projeto fiquem nas mãos dos moradores. O designer deve exercer seu papel de dar suporte técnico, evitando interferir nas soluções que reflitam aspectos simbólicos dessas fragilizadas populações. ${ }^{10}$

Ao invés de mera modificação territorial, o design aqui opera esboçando desvios e adaptações que não são, contudo, menos precisos ou efetivos na medida em que chegam a dirigir processos irreversíveis. Design torna-se um tipo especial de nomadismo: um movimento de "reação silenciosa" para que o meio e 
o cotidiano nesse meio sejam recomeçados de maneira invisível, sem nenhuma grande mudança de imediato.

Disso decorre uma reflexão sobre a vida contemporânea: se cada dia é mais recorrente a sensação de que "nunca há espaço para todos", talvez seja porque ainda tomamos o espaço como fim em si mesmo ao invés de meio. O que há de impreciso neste ou naquele espaço há de preciso no "estar" em si. Se na passagem do século 19 ao 20 houve uma transformação do espaço público - um ambiente a ser frequentado não mais como passagem contingente -, hoje assistimos a um deslocamento para "qualquer lugar" desde que seja a um mesmo lugar. Dito de outro modo, as narrativas contemporâneas são vivenciadas pelo imaginário que as expressa, pelos sentidos que as veicula e, portanto, numa dinâmica nômade de deslocamento: imagens que atuam sobre sensibilidades, organizando e fazendo proliferar modos de existir, de viver, por meio do diálogo constante e renovável entre tempos e narrativas que aparecem, numa ocasião ou noutra, anacrônicos e concomitantes entre si.

O que eu vejo nas ruas de São Paulo, retomando minha digressão inicial, é uma cena não familiar que permanece sempre a mesma porque eu e ela somos sempre diferentes. E percebo que cada pessoa ao meu redor está vivendo uma vida tão "invisível" quanto a minha - povoada com suas próprias ambições, amigos, rotinas e preocupações. Como um formigueiro alastrando no subsolo, abrem-se infinitas passagens para outras vidas que eu nunca saberia que existem, nas quais eu posso aparecer apenas uma vez como um borrão de luz que desaparece no tráfego urbano. Assim que eu experimento essa vertigem, começo a ir para a "deriva" e não mais reconheço a assim chamada "gente", porém pessoas diferentes para as quais todo gesto pode soar novo e decisivo.

Não é que não há fronteiras para o nômade, é que ele consegue desvencilharse delas para transformá-las em potência. Ao invés de satisfazer-se com objetivos e conquistas, presta-se atenção às ocasiões singulares, cada qual trazendo consigo seu próprio meio e duração. Claro que sempre resta nas partidas um sentimento de busca e de possível retorno. Mas partir e voltar não mais se distinguem quando sabemos que haverá outro lugar, outro tempo e outras ocasiões necessariamente diferentes do que eram, mas onde poderemos reconhecer uma parte de onde viemos e do que somos. Um retorno indistinguível de um passo adiante.

Acredito nos lugares, não os grandes e sim os pequenos, os desconhecidos, no estrangeiro bem como no interior. Acredito naqueles lugares sem importância nem nome, talvez designados apenas porque lá não existe nada, enquanto por toda parte existe algo. Acredito na força daqueles lugares porque ali nada acontece mais, e ainda não acontece nada. Acredito no oásis do vazio, não afastado, mas no meio desta plenitude aqui. - Peter Handke

\section{Marcos Beccari}

Doutorando em educação na USP. Mestre em design pela Universidade Federal do Paraná (UFPR).

marcosbeccari@usp.br 